\title{
Oral Diseases and Liver Pre and Post-Transplantation Disorders
}

\section{Liliane Elze Falcão Lins Kusterer}

Bahiana School of Medicine and Public Health, Salvador, Bahia, Brazil

Liver Transplant Clinic, Federal University of Bahia-UFBA School of Medicine, Salvador, Bahia, Brazi

\begin{abstract}
Cirrhotic patients with a poor state of oral health, particularly those with chronic infections, may have an increased susceptibility to systemic infections in pre and post liver transplantation. The literature correlates a poor state of oral health with liver cirrhosis, possibly leading to a potential worsening of the patient's general condition while awaiting transplantation. The immunosuppressant therapy, similarly, may increase the risk of oral infection and periodontal disease in this group of patients. The aim of this paper is to discuss stomatological disorders in the pre and post- liver transplantation period, considering dental treatment essential to prevent systemic complications in cirrhotic patients awaiting liver transplantation as well in transplanted patients.
\end{abstract}

Keywords: Liver Transplant; Oral surgery; Oral Pathology; Oral Health

\section{Introduction}

Infections have been shown to be a frequent cause of morbidity and mortality in postoperative liver transplantation (LT), and immunosuppression therapy can increase a patient's risk of infection. In a prospective study [1], including 170 cirrhotic hospitalized patients, the prevalence of bacterial infection during hospitalization was $47.06 \%$. Furthermore, infection is a leading cause of decompensated cirrhosis in patients awaiting liver transplantation and has been associated with the degree of severity of liver disease [1]. The literature correlates a poor state of oral health with liver cirrhosis, possibly leading to a potential worsening of the patient's general condition while awaiting transplantation. Some patients may be in a debilitated state of oral health due to the severity of liver disease, while others may have their oral health compromised by post-transplant immunosuppressant therapy [2-5]. The aim of this paper is to discuss stomatological disorders in the pre and post- liver transplantation period, considering dental treatment essential to prevent systemic complications in cirrhotic patients awaiting liver transplantation as well in transplanted patients.

\section{Risk of systemic infection}

Cirrhotic patients with a poor state of oral health, particularly those with chronic infections, such as periapical lesions and abscesses, may have an increased susceptibility to systemic infections in the pre-LT and/or post-operative LT period [5], although there exists little data in the literature which would substantiate this claim [6,7]. Moreover, periodontal disease may be related to a range of systemic complications [8-10], and a case of pyogenic liver abscess with probable etiology of odontogenic infection in a patient with a history of severe periodontitis and periodontal pocket has been reported in the literature [11]. Using immunohistochemical analysis, many bacteria known to cause periodontal disease were identified in organs such as the liver, heart and kidneys in this case report.

\section{Management of excessive bleeding}

While protocols and oral health evaluations are mentioned in the literature [2-5], no consensus exists regarding treatment, nor is there any on the indication of dental surgery in cirrhotic patients due to the risk of hemorrhagic complications or other adverse circumstances during the healing process following tooth extraction $[12,13]$. One study conducted in Germany [13] has reported hemorrhagic complications and scarring in $23.1 \%$ of patients with liver cirrhosis which contraindicates surgical treatment of cirrhotic patients. However, a Brazilian report describes excellent results in the treatment of oral lesion in chronic liver disease (CLD) patients using a multidisciplinary approach [5]. According to the authors, the results have shown favorable outcomes with few complication and lower mortality rate among the group of treated patients, although, some patients with more advanced liver disease were not treated due to loss of follow-up, refusal or unavailability of resources. However, protocols need to be established in order to care for patients with liver cirrhosis, and, in cases where surgery is required, extractions should be performed in a hospital environment with the administration of blood products when necessary, principally in cases of severe liver disease. The postoperative period must be accompanied by the transplant clinic's hepatology team, allowing for a proper assessment of liver and kidney function, and appropriate management of any complications that arise [5]. For these authors, dental treatment, coordinated in conjunction with the transplant team, was a statistically significant factor that demonstrated better rates of survival in patients with severe liver disease, although in less severe cases no statistically significant difference was observed.

\section{Dental treatment and antibiotic prophylaxis}

With respect to antibiotic prophylaxis, although there is no consensus in the literature, the use of antibiotic therapy before dental treatment is generally indicated [5,14]. It is important to notice that the foci of odontogenic infections are not treated solely with antibiotic therapy. Effective treatment requires the removal of root fragments, abscesses and intraosseous lesions, as well as treatment for periodontitis. Untreated foci, associated with a poor level of oral hygiene, increase susceptibility to infection, especially in patients with a compromised overall state of health, as well as in those who are immunocompromised. Several publications have suggested that oral infection, especially periodontitis, is a potential contributing factor to systemic complications [8] and the association between periodontopathic bacteria and bacterial endocarditis is well-stablihsed.

Corresponding author: Liliane Elze Falcão Lins Kusterer, Bahiana School of Medicine and Public Health, R. Frei Henrique, 8 Nazaré - Salvador, Bahia CEP: 40050-420, Brazil, E-mail: liliane@linsreabilitacao.com.br

Received September 26, 2011; Accepted October 31, 2011; Published November 03, 2011

Citation: Lins Kusterer LEF (2011) Oral Diseases and Liver Pre and PostTransplantation Disorders. J Transplant Technol Res S1:001. doi:10.4172/21610991.S1-001

Copyright: (C) 2011 Lins Kusterer LEF. This is an open-access article distributed under the terms of the Creative Commons Attribution License, which permits unrestricted use, distribution, and reproduction in any medium, provided the original author and source are credited. 
The case of hepatic pyogenic abscess reported previously, caused by periodontal disease bacteria, confirms this correlation [11].

The effect of antibiotic prophylaxis on the risk of surgical siteinfection (SSI) in liver orthotopic transplant was evaluated by a prospective study that included a population of all consecutive patients who underwent deceased-donor whole LT in 11 Sapanish hospitals between August 2003 and September 2005. A total of 1222 patients were included in this survey and 127 episodes of surgical site infection were recorded in 107 patients, being the predominant infection sites incisional SSI (42\%) and peritonitis (39\%), followed by intra-abdominal abscess (16\%) and hepatic abcess (10\%). The risk of developing at least 1 SSI was 8.8 per 100 patients, and the cumulative incidence of SSI was 10.3 occurrences per 100 transplanted patients. One hundred twenty-four organisms were recovered from 85 occurrences of SSI, with 21 of those being polymicrobial infection. Considering the different microorganisms, $38 \%$ of the pathogens recovered were gram-positive cocci, $52 \%$ were gram-negative rods, and $8 \%$ were Candida ssp. It is important to notice that Enterococcus spp., Escherichia coli, Stafilococcus aureus, and Acinetobacter baumannii were the most frequent isolated pathogens [15]. It should be considered that the oral cavity may act as a reservoir for "non- oral" pathogenic bacteria related to systemic infections. Corroborating with this assertive, a Brazilian study determined the prevalence and levels of pathogenic bacteria in the subgingival biofilm of chronic periodontitis lesions and healthy periodontal sites using the checkerboard DNA-DNA hybridization technique. In this survey, 200 samples of subgingival biofilm from sites with periodontitis and 200 samples from healthy sites of 14 patients with chronic periodontitis, as well as 200 samples from 3 periodontally healthy patients were obtained. The results has shown that Corynebacterium diphtheriae, Escherichia coli, Enterococcus faecalis, Pseudomonas aeruginosa and Staphylococcus aureus were significantly more prevalent in patients with periodontal disease compared to healthy subjects $(\mathrm{p}<0.05)[16]$.

Although literature needs to be more consistent correlating dental complication with pre and post-transplantation disorders, in a survey of 294 transplant clinics in the United States, 38\% reported infections of dental origin that resulted in the postponement or cancellation of a scheduled transplantation procedure, and $27 \%$ of clinics reported at least one episode of sepsis post-transplantation with a probable odontogenic cause [14]. This survey has demonstrated the need for more concerted efforts made by multidisciplinary transplant teams with respect to patient oral health. Corroborating with this assertive, a cross-sectional analysis [5] has shown that oral treatment appears to be associated with a reduction in mortality in cases of severe liver disease.

\section{Periodontal and dental diseases in cirrhotic patients}

The evolution of periodontal disease and oral infections can be influenced by many factors such as a lack of access to proper dental care and education level. In addition, the use of medications may result in a reduction of salivary flow as well as stress, cognitive loss and depression may contribute to tooth decay [17-19]. The literature $[2,4,5]$ describes a high frequency of advanced periodontal disease and low rates of satisfactory oral health status in patients awaiting liver transplantation. Barbero et al. [2] have determined the oral health profile of $80 \mathrm{LT}$ patients and found deficient dental hygiene in $85 \%$ of subjects while $45 \%$ were affected by advanced periodontal disease and $12 \%$ by a chronic gingivitis. In addition, dental caries and periapical lesions were observed in $67 \%$ and in $20 \%$ of the subjects, respectively. Guggenheimer et al. [4] has examined 300 candidates to LT and found association between dental plaque and use of diuretic which may reduce salivary flow and contribute to development of oral diseases.
Lins et al. [5] has evaluated 131 cirrhotic patients and observed a high prevalence of poor oral health status as well as odontogenic infection among those liver transplant candidates. Of the examined patients, $48 \%$ had xerostomia, $52 \%$ had periodontitis, $48 \%$ had periapical lesion, $45 \%$ had abscess and $45 \%$ had roots fragment representing potential sources of infection.

It is important to note that some studies correlate hepatitis $\mathrm{C}$ virus (HCV) infection and Alcoholic Liver Disease (ALD) [13,20,21] with a poor state of oral health. In ALD [13,20], the underlying disease may be associated with social behavior that contributes to a worsening of patients' oral health. Considering $\mathrm{HCV}$ infection, it has been reported a reduction of salivary flow in 50 per cent of hepatitis $\mathrm{C}$ infected subjects which promotes the deposition and retention of dental plaque [21] Lins et al. [5] have found liver disease secondary to HCV infection to be the most frequent indication of LT in cirrhotic patients followed by ALD which may contribute to elevate frequency of periodontal disease and reduction of salivary flow in that survey [5]. Moreover, the long wait period associated with the transplant list in Brazil may lead to complications, such as dental lesions. Corroborating with this assertive, Guggenheimer et al. [4] has reported that intervals of more than one year since the last dental treatment, smoking and diuretic therapy seem to be the most significant factors leading to poor oral health in LT patients.

Liver transplantation patients have a high frequency of partially edentulous dental condition $[2,4,5]$ and, in some cases, patients are completely edentulous in the upper dental arch, presenting denture stomatitis as a consequence of poor hygiene in their denture prosthesis. In Brazil [5], considering 131 cirrhotic patients, the high frequency of a partially edentulous dental condition, periodontal disease and caries, as well as a high Decayed, Missing and Filled Teeth index (DMFT index), 18.9 in males and 16.9 in females, demonstrated that cirrhotic patients on the transplant waiting list in Northeast are far from reaching the global targets set for 2010 as established by the World Health Organization, which estimates that in an age range of $35-44,96 \%$ of patients should present at least 20 functional teeth and less than $2 \%$ should be edentulous [22].

\section{Oral lesion in cirrhotic patients}

The evidence of mucosal lesions [3-5] in cirrhotic patients indicates the need for stomatological examination in order to prevent systemic infection, as well as oral cancer, especially in cases of trauma associated with poor hygiene when patients wear dentures. Cases of denture stomatitis lesions [5] were associated with poor hygiene in the upper denture prosthesis, which corroborates with findings in the literature associating poor hygiene with the proliferation of Candida albicans, characterized by an enzymatic action on tissue that leads to lesion development [23]. In transplanted patients, candidiasis may result from immunosuppression therapy and virulence of fungi pathogens. A recent survey has demonstrated that Candida's prevalence in the oral cavity of kidney or liver transplant recipients is higher than in immunocompetent control subjects [24]. Oral ulcers has also been recognized as a possible complication after transplantation due the use of immunosuppressant such tacrolimus, everolimus and mycophenolate mofetil, however the reports are controversial [25-31]. A multidisciplinary approach is essential to evaluate the replacement of such drugs in case of stomatitis in post-transplant patients.

The literature correlates herpes simplex virus, Epstain-Barr virus (EBV) and cytomegalovirus (CMV) infections with oral ulcers and stomatitis in patients undergoing solid organ transplantation $[3,32,33]$. Corroborating with this assertive, a survey with 29 patients, 
who presented oral stomatitis, after kidney or liver transplantation, detected CMV infection in 13 individuals (46.43\%). It is important to notice that some oral lesion due to viral infection may present an atypical appearance and biopsy is strongly necessary in diagnosis and treatment of the patient. A case of a herpes simplex oral lesion whose differential diagnosis included chronic hyperplastic candidiasis, nodular leukoplakia and malign neoplasm has been reported [34].

Studies of cancer in transplants recipients receiving immune suppression have been reported [35,36]. These studies intended to elucidate which cancer were truly associated with immune deficiency. A meta-analysis study evaluated cancer incidence in published populationbased studies of people with HIV/AIDS, and organ transplants recipients [36]. Considering nasopharyngeal cancer, only one case of such cancer was reported in transplant recipients. Interestingly, the risk of lip cancer after solid organ transplantation is 30 times that of HIV/AIDS. An Australian cohort of 8.162 kidney transplant recipients found a prevalence of 203 squamous cell carcinoma of the lip, after transplantation [37]. Considering liver transplantation, a Canadian cohort has pointed that liver transplant recipients had cancer incidence rates 2.5 higher than those of general population [38]. It is important to notice that a large numbers of cancers occur associated with oncogenes viruses such as EBV, CMV, human herpesvirus 8, hepatitis viruses $\mathrm{B}$ and $\mathrm{C}$ and human papillomavirus [36] that are also correlated with oral lesions or may cause xerostomia which is implicated in development of caries and periodontal disease.

The survival rates in transplantation have increased with the addition of cyclosporine $\mathrm{A}$ (CsA) and tacrolimus to the posttransplantation immunosuppressive protocol. As a side effect, gingival overgrowth has been observed as a result of immunosuppressive therapy with CsA [39]. In the same study, the gingival overgrowth in tacrolimus-treated patients was greater compared to the controls, although significantly lower than CsA-treated patients. The authors suggest that CsA-treated patients with gingival overgrowth might benefit from replacing CsA with tacrolimus to prevent periodontal diseases. Besides gingival overgrowth, other side-effects related to CsA therapy have been reported such as oral mucosa pathologies related with bacterial, viral and fungal infections [40].

It is known that one of the complications in Post-transplantation patients is the loss of bone mass. In a case-control survey [41] liver cirrhotic patients demonstrated greater alveolar bone loss compared to health controls. The authors suggest that the bone loss may be associated to liver disease and the level of cytokines associated with liver cirrhosis. In the same study, a trend for inverse correlation between the time interval since liver transplantation and the severity of bone loss was observed which could be justified by the restoration of liver function, the reduction of cytokines levels or the association of immunosuppressive medication. There is evidence that periodontal pathogens are often found in periodontally health people for long periods being part of normal oral microbiota. In this context, periodontal disease is a consequence of a disruption in the hostmicrobe homeostasis associated with health [42]. Perform dental treatment is feasible before transplantation, since immunossupression decreases patient' resistance to systemic infection [5]. In case of pre or post-transplants patients, dental treatment requires antibiotic prophylaxis, since those patients are at increased risk for bacterial, viral and fungal infections. It is necessary to educate those patients to follow oral hygiene routine and prescribe fluoride as well antimicrobial rinses when appropriate in other to control periodontal disease.

\section{Concluding Remarks}

In conclusion, there are innumerous stomatology complications in
Pre and Post- liver transplant that require a stomatologist to become an integral part of the overall care of cirrhotic patients before and after liver transplantation. In Brazil, transplant clinics still do not offer an integrated dental treatment component, in a coordinated effort together with transplant teams. It would be necessary to require both dental care in an outpatient environment as well as hospitalization to perform dental surgery in the fields of Surgery and Maxillofacial Traumatology. In outpatient hepatology clinics, where many patients are treated for viral hepatitis, there still exists a need for preventive actions to promote a better state of oral health in those patients. Literature $[2,3,4,5]$ have determined that patients on LT lists present a poor state of oral health, requiring preventive assessment and stomatological treatment and this treatment appears to be associated with a reduction in mortality in cases of severe liver disease [5]. However, the authors point that further studies examining co-morbidity, age and disease severity are necessary in order to assess the true impact of the presence and/or treatment of oral health status on the survival rate of cirrhotic patients awaiting LT. The present review has demonstrated evidence in support of the recommendation that transplant teams should include stomatologists or dentists in their multidisciplinary groups.

\section{References}

1. Caly WR, Strauss E (1993) A prospective study of bacterial infections in patients with cirrhosis. J Hepatol 18:353-358.

2. Barbero P, Garzino Demo MG, Milanesio M, Ottobrelli A (1996) The denta assessment of the patient waiting for a liver transplant. Minerva Stomatol 45 431-439.

3. Díaz-Ortiz ML, Micó-Llorens JM, Gargallo-Albiol J, Baliellas-Comellas C Berini-Aytés L, et al. (2005) Dental health in liver transplant patients. Med Oral Patol Oral Cir Bucal 10: 66-76.

4. Guggenheimer J, Eghtesad B, Close JM, Shay C, Fung JJ (2007) Dental health status of liver transplant candidates. Liver Transpl 13:280-286.

5. Lins L, Bittencourt PL, Evangelista MA, Lins R, Codes L, et al. (2011) Ora health profile of cirrhotic patients awaiting liver transplantation in the Brazilian Northeast. Transplant Proc 43:1319-1321.

6. Reyna J, Richardson JM, Mattox DE, Banowsky LH, Nicastro-Lutton JJ (1982) Head and neck infection after renal transplantation. JAMA 247:3337-3339.

7. Bassiri AG, Girgis RE, Theodore J (1996) Actinomyces odontolyticus thoracopulmonary infections. Two cases in lung and heart-lung transplant recipients and a review of the literature. Chest 109:1109-1111.

8. Li X, Kolltveit K, Tronstad L, Olsen I (2000) Systemic diseases caused by ora infection. Clin Microbiol Rev 13:547-558.

9. Seymour GJ, Ford PJ, Cullinan MP, Leishman S, Yamazaki K (2007) Relation between periodontal infections and sistemic disease. Clinical Microbiology and Infection 13:3-10.

10. Saremi A, Nelson RG, Tulloch-Reid M, Hanson RL, Sievers ML, et al. (2005) Periodontal desease and mortality in type 2 diabetes. Diabetes Care 28:27-32.

11. Ohyama H, Nakasho K, Yamanegi K, Noiri Y, Kuhara A, et al. (2009) An unusua autopsy case of pyogenic liver abscess caused by periodontal bactéria. Jpn J Infect Dis 62:381-383.

12. Schmelzeisen R, Eckardt A, Knoll M, Girod S (1991) Special considerations in dental surgery procedures on organ transplantation patients. Dtsch Z Mund Kiefer Gesichtschir 15: 431-434

13. Niederhagen B, Wolff M, Appel T, von Lindern JJ, Bergé S (2003) Location and sanitation of dental foci in liver transplantation. Transpl Int 16:173-178.

14. Guggenheimer J, Mayher D, Eghtesad B (2005) A survey of dental care protocols among US organ transplant centers. Clin Transplant 19:15-18.

15. Asensio A, Ramos A, Cuervas-Mons V, Cordero E, Sánchez-Turrión V, et al (2008) Effect of antibiotic prophilaxis on the risk of surgical site infection in orthotopic liver transplant. Liver Transpl 14: 799-805.

16. Souto R, Andrade AFB, Uzeda M, Colombo APV (2006) Prevalence of "non-oral" pathogenic bactéria in subgingival biofilm of subjects with chronic periodontitis. Braz J Microbiol 37: 208-215. 
Citation: Lins Kusterer LEF (2011) Oral Diseases and Liver Pre and Post-Transplantation Disorders. J Transplant Technol Res S1:001. doi:10.4172/2161-0991.S1-001

Page 4 of 4

17. Guggenheimer J, Moore PA (2003) Xerostomia:Etiology, recognition and treatment. J Am Dent Assoc 134:61-69.

18. Kinane D, Chestnutt IG (2000) Smoking and Periodontal Disease. Crit Rev Oral Biol Med 11:356-365

19. Olbrisch ME, Benedict SM, Ashe K, Levenson JL (2002) Psychological assessment and care of organ transplant patients. J Consult Clin Psychol 70:771-783.

20. Plachetzky U, Novacek G, Tuppy F, Walgram M, Volgelsang $H$, et al (1991) Ergebnisse der Herdsuche und Herdsanierung im Bereich der Zahn-, Mundund Kieferheilkunde bei 50 Lebertranplatationkadidaten. Z Stomatol 89: 309317.

21. Coates EA, Brennan D, Logan RM, Goss AN, Scopacasa B, et al. (2000) Hepatitis C infection and associated oral health problems. Aust Dent J 45:108-

22. WHO (World Health Organization) (1993) Dental Caries Levels at 12 Years. WHO/ORH (Oral Health)/EIS (Epidemiological Information System)/12-yearold book. Geneva: WHO

23. Webb BC, Thomas CJ, Willcox MD, Harty DW, Knox KW (1998) Candidaassociated denture stomatitis. Aetiology and management: a review. Part 1. Factors influencing distribution of Candida species in the oral cavity. Aust Dent J 43: 45-50.

24. Olczak-Kowalczyk D, Pawłowska J, Garczewska B, Smirska E, Grenda R, et al. (2010) Oral candidiasis in immunosuppressed children and young adults after liver or kidney transplantation. Pediatr Dent 32:189-194

25. Morard I, Dumortier J, Spahr L, Hadengue A, Majno P, et al. (2007) Conversion to sirolimus-based immunossupression in manteinance liver transplantation patients. Liver Transpl 13: 658-664.

26. Ram R, Swarnalatha G, Neela P, Dakshinamurty KV (2008) Sorolimus-induced Aphthous Ulcers which disappeared with conversion to Everolimus. Saudi J Kidney Dis Transpl 19: 819-820.

27. Macario-Barrel A, Tanasescu S, Courville Ph, Redonnet M, Cordel N, et al. (2001) Ulcerations buccales chez un maladie recevant du tracolimus. Annales de Dermatologie et Vénéréologie 128: 1327-1329

28. Habbib N, Salaro C, Al-Ghaithi K, Phelps RG, Saggar S, et al. (2010) Severe aphthous stomatitis associated with oral calcineurin and mTOR inhibitors. In J Dermatol 49: 91-94.

29. Hernández G, Jiménez C, Arriba L, Moreno E, Lucas M (2001) Resolution of oral ulcerations after decreasing the dosage of tacrolimus in a liver transplantation recipient. Oral Surg Oral Med Oral Pathol Oral Radiol Endod 92: 526-531
30. Vermeulen T, Rodrigus IE, Vrints CJ, Conraads V (2010) Severe Stomatitis complicating immune-suppressive switch after cardiac transplantation. Acta Chir Belg 110: 339-341.

31. Weng RR, Foster CE, Hsieh LL, Patel PR (2011) Oral ulcers associated with mycophenolate mofetil use in a renal transplant recipient. Am J Health Syst Pharm 68: 585-588

32. López-Pintor RM, Hernández G, de Arriba L, Morales JM, Jiménez C, et al. (2009) Oral Ulcers during the cause of cytomegalovirus infection in renal transplant recipientes. Transplant Proc 41: 2419-2421

33. Olczak-Kowalczyk D, Pawłowska J, Cukrowska B, Kluge P, Witkowska-Vogt E, et al. (2008) Local presence of cytomegalovirus and Candida species vs oral lesions in liver and kidney transplant recipients. Ann Transplant 13:28-33

34. Burke EM, Karp DL, Wu TC, Corio RL (1994) Atipical oral presentation of herpes simplex vírus infection in a patient after orthotopic liver transplantation. Eur Arch Otorhinolaryngol 251: 301-303.

35. Vajdic CM, van Leeuwen MT (2009) Cancer incidence and risk factors afte solid organ transplantation. Int J Cancer 125: 1747-1754

36. Grulich AE, van Leewen MT, Falster MO, Vajdic CM (2007) Incidence of cancers in people with HIVIAIDS compared with immunosuppressed transplant recipients: a mata-analysis 370:59-67.

37. van Leeuwen MT, Grulich AE, McDonald SP, McCredie MR, Amin J, et al. (2009) Immunosuppression and other risk factors for lip cancer after kidney transplantation. Cancer Epidemiol Biomarkers Prev 18:561-569.

38. Jiang Y, Villeneuve PJ, Fenton SSA, Schaubel DE, Lilly L, et al. (2008) Live transplantation and subsequent risk of cancer: findings from a Canadian cohort study. Liver Transpl 14: 1588-1597.

39. Tyrzyk S, Sadlak-Nowicka J, Kedzia A, Bochniak M, Szumska-Tyrzyk B, et al. (2004) Clinical and mycological examinations of oral mucosa in cyclosporine A treated patients after renal transplantation. Przegl Lek 61:467-472.

40. Oettinger-Barak O, Barak S, Machtei EE, Ardekian L, Baruch Y, et al. (2001) Periodontal changes in liver cirrhosis and post-transplantation patients. I: clinical findings. J Periodontol 72 : 1236-1240.

41. Oettinger-Barak O, Barak S, Machtei EE, Ardekian L, Baruch Y, et al. (2002) Periodontal changes in liver cirrhosis and post-transplantation patients. II: Radiographic findings. J Periodontol 73: 313-316.

42. Armitage GC (2010) Comparison of the microbiological features of chronic and aggressive periodontitis. Periodontol 53:70-88.
This article was originally published in a special issue, Post-Transplantation Disorders handled by Editor(s). Dr. Piergiorgio Messa, IRCCS Fondazione Ca' Granda, Italy; Dr. Cheguevara I Afaneh, Weill Cornell Medical College, USA; Dr. Shaoyan Hu, The Children's Hospital of Soochow University, China 